\title{
Glanzmann's Thrombasthenia: A Review of Literature
}

\author{
Hansa Dhar ${ }^{1}$, Asha Santosh ${ }^{2}$
}

\begin{abstract}
Introduction: Glanzmann's thrombasthenia is an inherited autosomal recessive bleeding disorder in which there is a deficiency of platelet glycoprotein Gpllb/llla. These receptors allow platelets to aggregate by sticking to each other, releasing granular contents to potentiate the process of clotting. Platelets are not able to clump together when stimulated, resulting in failure to form platelet aggregates. In such instances, bleeding time is prolonged and the clot retraction is defective, resulting in increased bleeding tendency. GT is diagnosed by tests that determine whether there is a deficiency of the $\mathrm{a} 11 \mathrm{~b} \beta 3$ (Gpllb/llla) receptor. The diagnosis is confirmed mainly by flow cytometry and monoclonal antibodies. In the platelet function analyzer 100 (PFA-100), platelets fail to plug on the filter, as platelet aggregation response is defective. The condition may present in early childhood causing repeated nasal bleeds, or in adulthood as menorrhagia, antenatal, and postpartum hemorrhage. Patients may require many leukocyte-depleted blood products during bleeding episodes.

Objectives: Objectives of this review article is to understand the implications of Glanzmann's thrombasthenia, its pathogenesis, diagnostic modalities and treatment options as it is a rare platelet disorder. Surgeons have to be on the alert if the case is a Glanzmann's thrombasthenia, as uncontrolled hemorrhage not responding to usual treatment can have fatal consequences.

Materials and methods: An extensive search and review of current literature was undertaken via PubMed and EMBASE to know the historical background with its latest management options available.

Results and evidence: Studies have suggested that GT is a hereditary disorder occurring predominantly in consanguineous populations with female preponderance.

Remarks and conclusions: As consanguinity is very high in this part of the world awareness among clinicians of this medical disorder is necessary to avoid unanticipated hemorrhage and its untoward complications.
\end{abstract}

Keywords: Epistaxis, Glanzmann's thrombasthenia, Menorrhagia, Mucocutaneous bleeding, Platelet transfusion, rFV11a.

Journal of South Asian Federation of Obstetrics and Gynaecology (2019): 10.5005/jp-journals-10006-1665

\section{HISTORY}

In 1918 in a tiny Swiss village-Le Valais, Dr Eduard Glanzmann (a pediatrician) first reported the incidence of Glanzmann's thrombasthenia in children. He observed prolonged bleeding time and an isolated appearance of platelets on a peripheral blood smear. ${ }^{1}$ In 1956, Braunsteiner and Pakesch observed platelets of normal size that did not help in clot retraction. ${ }^{2}$ Later, Caen et al. noted that abnormal platelet aggregation was the primary feature in $\mathrm{GT}^{3}$ Absence of both platelet aggregation and clot retraction was termed as type-I and absence of aggregation but residual clot retraction as type-II disease in $1981 .{ }^{4}$ Incidence of GT is around $1 / 10,00,000$ and is seen mostly in consanguineous marriages. ${ }^{5,6}$

\section{Pathophysiology}

Each platelet has 50-100 glycoprotein receptors, which help in the formation of clot by an interaction between the cellular components of blood and coagulation proteins. ${ }^{7,8}$ Activation of these receptors is dependent on stimulation by ADP (adenosine diphosphate), epinephrine, collagen, or thrombin.

Platelets have no cell nucleus but they are fragments of cytoplasm derived from the megakaryocytes of the bone marrow. The inactivated platelets are biconvex discoids (lens-shaped) with a greatest diameter of 2-3 $\mu \mathrm{m}$. The platelet membrane contains receptors for collagen, vessel wall von Willibrand factor (vWF), and fibrinogen. Their cytoplasm contains actin, myosin, glycogen, lysosomes, and two types of granules. Dense granules (delta granules) contain serotonin, ADP, and adenine nucleotides; alpha granules contain clotting mediators such as factor V, factor V11, fibrinogen, fibronectin, platelet-derived growth factor, and chemotactic agents. ${ }^{9}$
${ }^{1,2}$ Department of Obstetrics and Gynecology, Nizwa Hospital, Oman

Corresponding Author: Hansa Dhar, Department of Obstetrics and Gynecology, Nizwa Hospital, Nizwa, Oman, Phone: +968 92955360, e-mail: hdhar16@gmail.com

How to cite this article: Dhar $H$, Santosh A. Glanzmann's Thrombasthenia: A Review of Literature. J South Asian Feder Obst Gynae 2019;11(2):134-137.

Source of support: Nil

Conflict of interest: None

Injuries to the vessel wall cause platelets to bind to vWF. Platelets are activated by thrombin, and upon activation, they anchor to the collagen of the vessel wall. Their shape changes with the formation of pseudopodia, and after discharging their granules, they stick to other platelets by binding of $a 11 b \beta_{3}$ with vWF or fibrinogen. Platelet-activating factor (PAF) also helps in aggregation process. In GT, platelets cannot bind to fibrinogen and aggregation does not occur. ${ }^{10}$ As a result, no fibrinogen bridging of one platelet to another occurs, delaying clot retraction and resulting in potentially major mucocutaneous bleeding. ${ }^{11}$

GT is associated with the abnormal integrin $a 11 b \beta_{3}$. These are heterodimer transmembrane proteins that mediate cell adhesion and cell migration by attaching the cell cytoskeleton to the extracellular matrix. The integrin family of proteins consists of alpha and beta subtypes. Mutations causing GT affect either ITGA2B or ITGB3 genes. There are three grades of the disorder. Type 1 has severe deficiency with less than $5 \%$ Gpllb/llla receptors. Type II show a mild-to-moderate deficiency (5-20\%) of IIb/IIla receptors 
and type III has an almost normal amount of Ilb/IIla receptors but defective function. ${ }^{12}$

The mutational defects in genes may happen due to splicing abnormalities, insertions or deletions, non-sense mutation, and single amino-acid substitution. ${ }^{13-15}$ A Turkish study by Tokgoz et al. ${ }^{16}$ noted various further mutations in 7 of 20 Turkish GT patients (four novel and two previously described mutations) in ITGA2B and one novel mutation in ITGB3 besides the already documented mutations in literature.

There is a relatively high incidence of GT in various closed populations, such as the French gypsies, South Indians, Jordanian tribes, Arabs, and Iraqi Jews. ${ }^{12}$ Siddiq et al. ${ }^{11}$ observed a higher female preponderance for Glanzmann's thrombasthenia.

\section{Signs ANd Symptoms}

Bleeding tendency may be bruising in some individuals or severe fatal hemorrhage in others. Repeated episodes of epistaxis is a common occurrence in children noted to affect up to $9 \%$ of children. ${ }^{17}$

The main signs and symptoms are increased mucosal and gingival bleeding, menorrhagia, easy bruising, epistaxis, increased postpartum hemorrhage, and lifelong risk during surgical procedures. Bleeding may occur with minimal trauma or by harmless events such as sneezing, crying, coughing, eruption of a tooth, or even common cold. The condition is usually diagnosed in childhood. Menorrhagia in women and a rare bleeding complication after circumcision in men can also occur. Menorrhagia affects $25-30 \%$ of women, and post-circumcision bleeding may require platelet transfusion if uncontrolled..$^{18,19}$ Hematuria was reported in some but hemarthrosis and hematomas rarely occur. ${ }^{20}$ In some patients with angiodysplasia, gastrointestinal hemorrhages are also observed. Even unusual presentation of intracranial hemorrhage has been reported in some cases. ${ }^{21,22}$ Pregnancy along with GT is associated with a high risk of fetal and postpartum bleeding. Newborn thrombocytopenia (which is always transitory but serious) may occur sometimes. ${ }^{23}$ Women with GT are screened for platelet alloantibodies throughout pregnancy and postpartum. ${ }^{24}$

Increased prevalence in consanguineous populations in KSA was found by testing patients for GT by platelet immunophenotyping and comparing results with a PFA. In their study, ${ }^{25}$ platelet aggregometry revealed type I GT being the most common variety with female preponderance and they recommended using flow cytometry as a screening test.

Kazemzadeh et al. ${ }^{26}$ reported that Glanzmann's Thrombasthenia may modulate the symptoms of MTHFR gene mutation, but further investigations are recommended to identify the effects of thrombogenic polylorphisms on coagulation factors or on platelet glycoprotein in regions where hemorrhagic disorders are prevalent so as to analyze the interactions of these factors on bleeding tendencies.

\section{Diagnosis}

Platelet function is measured by flow cytometry, which is helpful for diagnosing inherited deficiency of platelet surface glycoprotein receptors. ${ }^{27}$ Other laboratory tests related to GT includes complete blood count, prothrombin time, activated partial thromboplastin time, platelet function analyzer 100 (PFA-100), monoclonal antibody assays, and platelet aggregation studies. The platelet count and coagulation test results should be normal. The red blood cell count may be decreased due to bleeding or concomitant iron deficiency. The bleeding time should be prolonged. On PFA-100 testing, the platelets fail to plug the collagen-based filter.

Ali et al. ${ }^{20}$ reported that GT can be diagnosed on the basis of platelet aggregometry when decreased platelet aggregation response to adenosine diphosphate (ADP), epinephrine and collagen and normal response to ristocetin (an antibiotic) is noted when compared to the Bernard-Soulier syndrome where a defective response to ristocetin and a normal von Willebrand assay response is elicited. Both these conditions cause a bleeding disorder due to platelet defects. In GT by failed aggregation and clot retraction and in the Bernard-Soulier, the defect lies in decreased platelet adhesion and not in aggregation. The Bernard-Soulier syndrome (BSS) is the second most common inherited platelet defect, where, at the molecular level, there is an absence of the platelet membrane glycoprotein complex, which is the receptor for vWF. This results in deficient binding of VWF to the platelet membrane at the sites of vascular injury, leading to defective platelet adhesion. The end result in both these disorders is the lack of formation of the primary platelet plug, together with an increased bleeding tendency. ${ }^{28}$ Few more sophisticated tests for diagnosis of GT such as western blotting, immunoprecipitation analysis, and gene sequencing are used in highly specialized centers in reference laboratories. ${ }^{29,30}$

Thromboelastography (TEG) is a method of testing the accuracy of blood coagulation by estimating the platelet function, clot strength, and fibrinolysis. It is used mainly in surgery and anesthesiology as a great tool for perioperative assessment of coagulation disorders. ${ }^{31}$

Narani ${ }^{32}$ demonstrated that perioperative TEG can prove to be an invaluable tool for bedside monitoring of coagulation status in patients with preexisting hemostatic disorders or in a profusely bleeding patient with a deranged hemostatic profile. TEG can monitor hemostasis and guide replacement of blood components and pharmacological agents. Thromboelastography measures the visco-elastic and mechanical properties of a developing clot. It detects all phases of the hemostatic activity from a single sample of blood. Clot formation, stabilization, retraction, and dissolution are displayed in graphical and numerical forms. ${ }^{33}$

Loroch et al., ${ }^{34}$ as well as researchers who studied recent advances in proteomics have documented several technologies for visualization, quantitation, and identification to elucidate the platelet processes, which are relevant to bleeding and clotting disorders, transfusion medicine, and regulation of angiogenesis. Platelets from GT patients showed less than $5 \%$ relative levels of the integrin subunit $\mathrm{a} 11 \mathrm{~b} \beta_{3}$.

\section{Treatment}

Leuko-reduced or human-leukocyte-antigen-matched platelets should be used, as patients need repeated platelet transfusion to avoid becoming refractory to this treatment. Platelet transfusion should be given immediately prior to the procedure. Recombinant factor VIla as an adjuvant can be used 48 hours postoperatively in refractory states with antibodies. ${ }^{35}$

Antifibrinolytics such as tranexamic acid and aminocaproic acid are used as adjuvants in emergency situations in GT and other bleeding dyscrasias. These drugs are utilized for enhancing hemostasis, whereas fibrinolysis results in hemorrhage due to the enhancement of clot breakdown. Both these drugs act by reversibly blocking the lysine-binding sites of plasminogen, thus preventing its activation to plasmin and thereby stopping the lysis of the 
polymerized fibrin. ${ }^{36}$ Antifibrinolytics such as tranexamic acid and aminocaproic acid are successfully used by maxillofacial surgeons in cases of various hematological disorders such as the Bernard Soulier syndrome, hemophilia, alcoholic cirrhosis of liver, hereditary angioedema, and the Trousseau syndrome. ${ }^{37,38}$ Wardrop et al. ${ }^{39}$ reported that the use of antifibrinolytics in hematology patients may be useful adjunts to platelet transfusions so that platelet use and the complications associated with their use can be reduced. The negative side-effect of both these drugs is the increased thromboembolic effects. A condition of acquired thrombasthenia due to glycoprotein IIb-IIla platelet antibodies may also result after platelet transfusion. ${ }^{40}$ Females with menorrhagia may be benefitted by using hormonal contraception.

Recombinant factor VIla with antifibrinolytic agents has been used both as a prophylactic and as a therapeutic measure in patients undergoing pelvic surgery, cesarean section, and vaginal delivery. Recombinant factor V11a acts on platelets in the absence of tissue factor to activate factor $1 X$ and $X$, thus enhancing thrombin generation. Recombinant factor V11a binds to the platelet surface and activate factor $1 \mathrm{X}$ and $\mathrm{X}$ to increase thrombin formation. The increase in thrombin formation stimulates platelet adhesion and platelet aggregation, which also include the Gpllb/Illa lacking platelets. The increased generation of thrombin may provide a strong signal for the recruitment of other platelets. ${ }^{41}$ Treatment with rFV11a is well tolerated but hugely expensive and increases the risk of thromboembolism. ${ }^{42}$

Recent treatment options include the use of Retiuximab, Bevacizumab, bone marrow transplantation, and stem cell therapy. ${ }^{43}$ Bevacizumab is a recombinant humanized monoclonal antibody that blocks angiogenesis by inhibiting vascular endothelial growth factor A (VEGF-A). ${ }^{44,45}$

Desmopressin raises the plasma levels of factor V111, vWF, and tissue plasminogen activator. It has no effect on platelet count or aggregation but enhances platelet adherence to the vessel wall. Desmopressin is successfully considered as a treatment option for various platelet disorders. No enough data are available to support the usage. ${ }^{46}$ Thalidomide is another interesting medical management lately experimented by several groups in management of angiodysplasia for severe and recurrent GI bleeds. The antiangiogenic effects suppress the expression of VEGF and promote vessel maturation. ${ }^{47}$

Permanent treatment is done by hematopoietic stem cell transplantation and donor cord blood transplantation. ${ }^{48}$ Gene therapy remains still the ultimate prospect of cure in these cases. The abnormalities of the cytoplasmic proteins that regulate the activation state of $a 11 b \beta_{3}$ for adhesion is yet to be explored. ${ }^{49}$ Kunicki et al. ${ }^{50}$ reported that some platelet receptor haplotypes along with use of proteomics and gene microarray can markedly reduce bleeding in cases of Von Willebrand disease and GT.

The management also includes avoidance of using antiplatelet agents such as aspirin and NSAIDs. The general measures are to use iron and folate supplements, hepatitis vaccine, and hormonal contraception. Minor bleeding can be controlled by local pressure, nasal packing, fibrin glues, or oral antifibrinolytics.

\section{ConcLusion}

Glanzmann thrombasthenia is a disease of clotting with lifelong risk of bleeding, especially during surgical procedures. Preoperative preparation of such cases by infusion of platelets, rFV11a and blood products can avoid life-threatening hemorrhage. In these cases, platelet count is normal, but clot retraction is abnormal. Stem cell transplantation and gene therapy will be the future therapies for treating this disease.

\section{Author Contribution}

Dr Hansa Dhar has contributed to data collection, manuscript preparation, research of the literature, and editing of themanuscript. Dr Asha has contributed to manuscript preparation and editing of the same. Both the authors approved the final version.

\section{References}

1. Glanzmann E. Hereditare Hamorrhgische thrombasthenie.Ein Beitrag Zur Pathologie der Blutplattchen. J Kinderkranken 1918;88:113.

2. Braunsteiner $\mathrm{H}$, Pakeschf F. Thrombocytoasthenia and thrombocytopathia. Old names and new diseases. Blood 1956;11:965-976.

3. Caen JP, Castaldi PA, et al. Glanzmann's thrombasthenia.I.Congenital bleeding disorders with long bleeding time and normal platelet count. Am J Med 1966;44:4-10. DOI: 10.1016/0002-9343(66)90003-9.

4. George JN, Caen JP, et al. Glanzmann's thrombasthenia: The spectrum of clinical disease. Blood 1990;75:1383-1395.

5. Nair S, Ghosh K, et al. Glanzmann's Thrombasthenia: Updated. Platelets 2002;13:387-393. DOI: 10.1080/0953710021000024394.

6. Kannan M, Saxena R. Glanzmann's thrombasthenia: An overwiew. Clin Appl Thromb Hemost 2009;15:152-165. DOI: 10.1177/ 1076029608326165.

7. Nurden AT. Glanzmann thrombasthenia. Orphanet J Rare Dis 2006;1:10. DOI: 10.1186/1750-1172-1-10.

8. Saxena R, Kannan M. Glanzmann's thrombasthenia: an overview. Clin Appl Thromb Hemost 2008;16.

9. Ghoshal K, Bhattacharyya M. Overview of Platelet Physiology: Its Hemostatic and Nonhemostatic Role in Disease Pathogenesis. The Scientific World Journal 2014;7(81):857-873. DOI: 10.1155/2014/781857.

10. Nurden AT, Fiore $M$, et al. Glanzmann thrombasthenia: a review of IT GA2B \& ITGB3 defects with emphasis on variants, phenotypic variability, and mouse models. Blood 2011;118(23):5996-6005. DOI: 10.1182/blood-2011-07-365635.

11. Siddiq S, Clark A, et al. A systematic review of the management and outcomes of pregnancy in Glanzmann thrombasthenia. Haemophilia 2011;17(5):e858-e869. DOI: 10.1111/j.1365-2516.2011.02516.x.

12. Ambreen M, Yasmeen S, et al. Glanzmann's Thrombasthenia. Ann Pak Inst Med Sci 2010;7(1):47-49.

13. Di Minno G, Coppola A, et al. Glanzmann's thrombasthenia (defective platelet integrin alpha 11b-beta3): proposals for management between evidence and open issues. Thromb Haemost 2009;102(6):1157-1164. DOI: 10.1160/TH09-04-0225.

14. Van de Vijver E, De Cuyper IM, et al. Defects in Glanzmann thrombasthenia and LAD-111(LAD-1/V) syndrome: the role of integrin $\beta 1$ and $\beta 3$ in platelet adhesion to collagen. Blood 2011;119:583-586. DOI: 10.1182/blood-2011-02-337188.

15. Fiore $M$, Nurden AT, et al. Clinical utility gene card for: Glanzmann thrombasthenia. Eur J Hum Genet 2012;20. DOI: 10.1038/ejhg. 2012.151.

16. Tokgoz H, Ozkan DT, et al. Novel mutations of the integrin a11b and $\beta_{3}$ genes in Turkish children with Glanzmann's thrombasthenia. Platelets 2015;26(8):779-782. DOI: 10.3109/09537104.2014.998994.

17. Recht $M$, Chitlur $M$, et al. Epistaxis as a common Presenting symptom of Glanzmann's Thrombasthenia, A Rare Qualitative Platelet Disorder: Illustrative case examples. Case Rep Emerg Med 2017;8796:425-430. DOI: $10.1155 / 2017 / 8796425$.

18. Trasi SA, Pathare AV, et al. The spectrum of bleeding disorders in women with menorrhagia: a report from western India. Ann Hematol 2005;84:339-342. DOI: 10.1007/s00277-004-0905-4.

19. Awidi AS. Delivery of infants with Glanzmann's Thrombasthenia and subsequent blood transfusion requirements: a follow up of 39 patients. Am J Hematol 1992;40:1-4. DOI: 10.1002/ajh.2830400102. 
20. Ali N, Moiz B, et al. Diagnostic tool for Glanzmann's thrombasthenia clinicopathologic Spectrum. J Coll Physicians Surg Pak 2008;18(2): 91-94.

21. Nurden AT, Ruan J, et al. A novel 196 Leu to Pro substitution in the beta 3 subunit of the alpha 11 beta integrim in a patient with a variant form of Glanzmann thrombasthenia. Platelets 2002;13:101-111. DOI: 10.1080/09537100220122466.

22. Kashiwagi $H$, Kunishima $S$, et al. Demonstration of novel gain-offunction mutation of a $11 \mathrm{~b} \beta 3$ : association with macrothrombocytopenia and Glanzmann thrombasthenia - like phenotype. Mol Genet Genomic Med 2013;1:77-86. DOI: 10.1002/mgg3.9.

23. Magudapathi C, Kannan S. Glanzmann's Thrombasthenia Complicating Pregnancy. J Obstet Gynaecol India 2014;64(1):3-5. DOI: 10.1007/s13224-012-0319-5.

24. Di Michele DM, Hathaway WE. Use of DDAVP in inherited and acquired platelet dysfunction. Am J Hematol 1990;33:39-45.

25. Majed KS, Al Nounou R. Glanzmann's Thrombasthenia, Correlation by Flow, Platelet Aggregometry and Platelet Function Assay (PFA). Bahrain Med Bull 2015;37(1):20-22. DOI: 10.12816/0014395.

26. Kazemzadeh $S$, Mohammadi R, et al. Methylene tetrahydrofolate Reductase Polymorphisms in Iranian Patients with Glanzmann's Thrombasthenia. Ira J Ped Hematol Oncol 2016;7(1):48-56.

27. Saboor M, Moinuddin M, et al. New Horizons in Platelets Flow Cytometry. Malays J Med Sci 2013;20(2):62-66.

28. Diz-Kucukkaya R. Inherited platelet disorders including Glanzmann thrombasthenia and Bernard-Soulier syndrome. Hematology Am Soc Hematol Edu Program 2013;2013:268-275. DOI: 10.1182/ asheducation-2013.1.268.

29. Linder MD, Frelinger AL 3rd, et al. Application of flow cytometry to platelet disorders. Semin Thromb Hemost 2004;30:501-511. DOI: 10.1055/s-2004-835671.

30. Peerschke El. The laboratory evaluation of platelet dysfunction. Clin Lab Med 2002;22:405-420. DOI: 10.1016/S0272-2712(01) 00008-7.

31. Robinson L, Gorton H. Thromboelastography: validation of the Thromboelastograph: 3000 and Thromboelastograph 5000. Br J Anaesth 2001;86:309-312.

32. Narani KK. Thrombelastography in the preoperative period. Indian J Anaesth 2005;49(2):89-95.

33. Chitlur M, Rivard GE, et al. Recommendations for performing thromboelastography/thromboelastometry in hemophilia: communication from the SSC of the ISTH. J Thromb Haemost 2014; 12:103-106. DOI: 10.1111/jth.12458.

34. Loroch S, Trabold K, et al. Alterations of the platelet ptoteome in type 1 Glanzmann thrombasthenia caused by different homozygous de IG frame shift mutations in ITGA2B. Thromb Haemost 2017;117(3): 556-569. DOI: 10.1160/TH16-07-0515.

35. Kumar N, Khan AA, et al. Glanzmann thrombasthenia and its perioperative management in head trauma: a rare and challenging situation. J Neuroanaesthesiol Crit Care 2016;3:52-55. DOI: $10.4103 / 2348-0548.173235$
36. Fernandes Gomes M, de Melo RM, et al. Surgical and clinical management of a patient with Glanzmann thrombasthenia: a case report. Quintessence Int 2004;35(8):617-620.

37. Brown SR. Antifibrinolytic Drugs (Aminocaproic acid and Tranexamic Acid): Treatment perspectives for Dental Surgery. Curr Oral Health Rep 2015;2:143-147. DOI: 10.1007/s40496-015-0051-1.

38. Yepes JF, Sullivan JA, et al. Hypercoagulability syndrome: What the dentist needs to know. Oral Surg Oral Med Oral Pathol Oral Radiol Endod 2007;104(1):3-11. DOI: 10.1016/j.tripleo.2006.11.023.

39. Wardrop D, Estcourt LJ, et al. Antifibrinolytics (Lysine analogues) for the prevention of bleeding in patients with haematological disorders (review). Cochrane Database Syst Rev 2013;7:CD009733.

40. Bloor AJ, Smith GA, et al. Acquired thrombasthenia due to GP11b111a platelet antibodies in a 4-year old child. Eur J Haematol 2006;76: 89-90. DOI: 10.1111/j.1600-0609.2005.00574.x.

41. Poon MC. Clinical use of recombinant human V11 (rFV11a) in the prevention and treatment of bleeding episodesin patients with Glanzmann's thrombasthenia. Vasc Health Risk Manag 2007;3(5): 655-664.

42. Rajpurkar M, Chitlur C, et al. Use of recombinant activated Factor V11 in patients with Glanzmann's Thrombasthenia: a review of the literature. Haemophilia 2014;20(4):464-471. DOI: 10.1111/hae. 12473.

43. Ayub M, Islam A. Glanzmann's Thrombasthenia; A Review study. PRJNHS 2016;2(1):46-52.

44. Marlu R, Barthelon J, et al. Long-term Therapy with Bevacizumab in a patient with Glanzmann's Thrombasthenia and Recurrent Digestive Bleeding due to Gastrointestinal Angiodysplastic Lesions. Am J Gastroenterl 2015;110(2):352-353. DOI: 10.1038/ajg. 2014.391.

45. Barre A, Dreanic J, et al. Is there a role for antiangiogenic therapy, bevacizumab, in the treatment of recurrent digestive bleeding due to angiodysplasia in Glanzmann's thrombasthenia? Haemophilia 2016;22(4):347-348. DOI: 10.1111/hae.12977.

46. Drachman JG. Inherited thrombocytopenia: when a low platelet count does not mean ITP. Blood 2004;103:390-398. DOI: 10.1182/ blood-2003-05-1742.

47. Duarte BKL, de Souza SM, et al. Thalidomide for the treatment of gastrointestinal bleeding due to angiodysplasia in a patient with Glanzmann's thrombasthenia. Hematology Reports 2017;9:53-56. DOI: 10.4081/hr.2017.6961.

48. Wilcox DA, White GC. Gene therapy for Platelet disorders: Studies with Glanzmann's Thrombasthenia. J Thromb Haemost 2003;1(11): 2300-2311. DOI: 10.1046/j.1538-7836.2003.00476.x.

49. Shattil SJ, Newman PJ. Integrins: dynamic scaffolds for adhesion and signaling in platelets. Blood 2004;104:1606-1615. DOI: 10.1182/ blood-2004-04-1257.

50. Kunicki TJ, Federici $A B$, et al. An association of candidate gene haplotype and bleeding severity in Von Willebrand disease (VWD) type 1 pedigrees. Blood 2004;104:2359-2367. DOI: 10.1182/blood2004-01-0349. 